\title{
MULHERES NA ARTE POPULAR MEXICANA: UMA CRÍTICA POSSÍVEL
}

Ronaldo de Oliveira Corrêa ${ }^{1}$

Sobre a obra resenhada:

Título: Mujeres en el arte popular: de promesas, traiciones, monstruos y celebridades.

Autora: Eli Bartra

México D.F.: UAM; Conaculta-Fonca, 2005

Eli Bartra é doutora em filosofia, participa do Sistema Nacional de Pesquisadores do México desde 1990. Fundou e coordenou a área de pesquisa "Mulher, identidade e poder", no Programa de Pós-graduação em estudos sobre a mulher, da Universiad Autónoma Metropolitana, UAM, na Cidade do México. Possui várias publicações sobre a temática da arte popular e sua interpretação, a partir das perspectivas teóricas feministas e de gênero.

O livro mujeres en el arte popular..., é caracterizado pela reflexão da autora sobre um conjunto de bens culturais artesanais, entendido como materialização das práticas de produção e reprodução das formas de estar e viver no mundo social, sua circulação e consumo em diferentes mercadosculturais, na República do México.

A investigação de Bartra caracteriza-se como etnometodológica, e seu campo multi-situado - abrangendo espaços urbanos e rurais. Estas características da investigação permitem que a autora percorra diferentes espaços e tempos encontre interlocução tanto na pesquisa de fontes históricas, quanto em entrevistas e relatos biográficos.

Por objeto, ou melhor, sujeitos, a autora toma as mulheres artesã, e sua produção plástica, de diferentes regiões da República do México. A justificativa para a escolha dos sujeitos tem por sustentação uma orientação epistemológica feminista - e que se desdobra, de alguma forma, nos Estudos de Gênero -, que diz respeito à visibilidade das mulheres - enquanto sujeitos históricos - nos mais distintos espaços e produções do social e do político.

Bartra define como espaço privilegiado para visibilizar este sujeito histórico, o da arte, mais especificamente, aquele classificado como da arte popular. A partir disso, ela define as margens do seu estudo: a arte popular e o

Doutor em Ciências Humanas pelo Programa de Pós-Graduação Interdisciplinar em Ciências Humanas PPGICH UFSC; professor da Universidade Federal do Paraná - UFPR. E-mail: olivecorrea@yahoo.com.br. 
feminismo, ou uma teoria feminista, que em alguns espaços acadêmicos, poderia ser chamada de pós-colonial. Com essas definições do tema, dos sujeitos e das teorias, a autora constroi seu panorama teórico. A partir deste, o mundo social, ou a realidade em que vivemos, seria marcado pelo patriarcado, e, o conhecimento produzido a respeito dessa realidade seria androcentrico. Ao propor este ponto de vista, a autora filia-se a um tipo de teoria feminista que entende a explicação do patriarcado como uma forma de configuração e explicitação de uma "cultura feminina".

Em resumo, a estratégia da autora recai na busca, por meio dos essencialismos das diferenças biológicas transmutados em desigualdades sociais, por uma resposta para as assimetrias que definem "lugares" sociais para homens e mulheres de grupos sociais subalternos ou periféricos nas sociedades complexas recentes. Nesta proposição, Bartra afirma que a "cultura feminina" co-existe tensamente com uma "cultura masculina", cujas características principais dessa última, seriam a opressão, a discriminação e a perseguição. Nesta tensa co-existencia, caberia à mulher - enquanto sujeito histórico - em meio à realidade androcêntrica do mundo social, denunciar o modelo hegemônico de dominação masculina, com o objetivo de gerar uma ação histórica de descrever, analisar e superar o patriarcado.

Essa perspectiva generalizadora sobre o patriarcado no mundo social recente, como caracterizado pela autora, encontra apoio em algumas teóricas do feminismo como Victoria Sau, citada pela autora. Todavia, esta abordagem do problema de investigação enfraquece o argumento do livro, a saber: da arte popular como um espaço de produção e reprodução de estratégias materiais e simbólicas, que constituiriam um tipo de "cultura feminina" libertária das mulheres dos povos originários e das camadas populares, nos mais diferentes espaços sociais, geográficos e políticos mexicanos.

Ao partir daquela generalização sobre o patriarcado, Bartra inviabiliza a raiz de seu argumento em duas direções. Por um lado, ao privilegiar a construção desse sujeito histórico - a mulher-artesã-mexicana - como oprimido e subjulgado, ela obscurece as estratégias cotidianas de resistência (ligadas aos espaços domésticos, às formas de participação nas atividades sociais e rituais, econômicas e políticas), que essas mulheres utilizam para dar conta de (ressignificar) um tipo de relação de dominação, seja ela patriarcal, ou não.

O que marca esta primeira perspectiva é o conceito de dominação que Bartra entende, estreitamente, como opressão dos homens em relação (sobre) as mulheres. Essa conceituação obscurece os conflitos, presentes no decorrer de seu texto, a respeito das relações de poder (ou desigualdades) que envolvem as mulheres e os grupos de mulheres que participaram da investigação, e destes com os circuitos de circulação cultural no México. Ou, ainda, encobre as reproduções de formas de dominação entre estas mesmas mulheres e, em relação aos homens, tomados como alteridade radical.

Ao que parece, Bartra desvia seu olhar destas disputas e assimetrias interna aos grupos de mulheres com quem estabelece uma interlocução teóricointerpretativa como uma forma de obscurecer as fissuras existentes em meio a integridade de sua tese a respeito de um mundo constituído pelo/no/a partir do patriarcado. Com isso, encobre os conflitos, as formas de negociação, e as 
respostas dadas por esses sujeitos sociais (mulheres e homens) em espaços urbanos e intercultuais.

Por outro lado, o argumento da autora reduz a potência da ação política dessas mulheres-artesãs, a saber: como autoras dos sistemas de objetos que desenvolvem e da participação na crítica e historiografia da qual são co-autoras. Dito de outra forma, Bartra obscurece as disputadas travadas em uma arena de conflitos, que constitue as identidades dessas mulheres, em espaços geográficos e políticos, sociais e econômicos, estéticos e éticos, em suas comunidades ou grupos e em relação aos circuitos de circulação cultural. Dessa forma, retira-se dessas mulheres mexicanas as possibilidades de atuarem como autoras de sua performatividade, ou como agentes de transformação de suas próprias trajetórias individuais e, igualmente, coletivas.

Ao colocar-se como interprete dos desejos dessas mulheres, a autora sistematiza suas gestualidades, e apresenta um breve sumário de suas trajetórias biográficas. Resulta dessa estratégia um tipo de emudecimento das vozes, das narrativas e das performances desse sujeitohistórico pretendido. Portanto, Bartra atua como mediação que "dá" ao (a) leitor (a) "uma representação de mulher-artesã-mexicana" a ser interpretada: aquela que inexiste como sujeito, mas está "presente" enquanto sistema de objetos questionadores de uma plástica "canonica" popular mexicana.

$\mathrm{Na}$ escritura do texto de Mujeres y el arte popular..., as vozes desses sujeitos-mulher não são grafadas junto a interpretação de suas gestualidades plásticas ou, mesmo, em relação as considerações conceituais realizadas pela autora, seja de ordem estética, seja ideológica. A escritura de Bartra, pois é tão machista quanto a realidade construída por ela, é patriarcal. Fica evidenciado que pretender uma escritura que transponha ou proponha uma alternativa a uma outra androcentrica é movimento complexo, tanto nos domínios da língua e suas alegorias, quanto no das palavras e seus usos.

Em função dessa estratégia de emudecimento, um tipo de reciprocidade é rompido entre a autora e os sujeitos de sua investigação. A evidência desse rompimento, é marcado na escritura do texto, como exposto acima. Outra, é materializada na utilização de apenas algumas frases daquelas mulheres no decorrer do texto. Estas "aparecem" como forma de sustentar uma afirmação da autora.

Em outro domínio do texto, aquele visual, algumas imagens foscas, opacas, são as marcas de existência corporal dessas mulheres. Os homens no texto verbal ou visual de Bartra são ausência quase total. Se sua ausência não fosse tão contundente, ou seja, se sua presença não se fizesse notar pela falta, acreditariamos que essas mulheres, de quem a autora nos fala, vivem em comunidades exclusivas de mulheres, em bolhas generificadas sociais e temporais. Mas, tal alegoria não se sustenta, pois, os sujeitos com que Bartra dialoga são mulheres que têm maridos e filhos, e compartilham com estes "não nominados" a lida, o dinheiro os significados trocados. De forma mais ampla, essas mulheres fazem parte de uma unidade social de produção, comunidade ou grupo social, onde homens e mulheres compartilham o mundo social.

O texto de Bartra converte-se, assim, na voz dominante (monológica) que explicita, por meio de dados geográficos e demográficos, históricos e 
etnográficos, os espaços de investigação, seja a casa, o ateliê, a praça ou o pueblo. Dados que tentam dar conta das diversas escolhas que homens e mulheres realizam para marcar sua passagem pelo mundo e pela história de suas comunidades e grupos sociais. Todavia, esses dados não tocam a vida daquelas mulheres de quem a autora fala (e tenta construir como herois de uma história épica) ou dos grupos e comunidades das quais estes sujeitos-mulher participam; ou ainda, dos circuitos culturais/simbólicos de um espaço geográfico, político e estético como a República do México.

Ademais desse exercício de com-vivência, nota-se que é na descrição dos objetos, com a minúscia de quem realiza uma crítica do objeto de arte, em que a autora sente-se mais à vontade. Apaixonadamente, evidencia as cores dos ex-votos (pintura votiva), guardados no templo dedicado a Virgem de Guadalupe na Cidade do México, apresenta as formas dos judas, utilizados nas festividades de Carnaval, nos bairros populares da mesma cidade. Junto a essas representações populares, relata sobre os ocumichos modelados em argila por artesãs em Michoacán, ou ainda, os alebrijes, criados por Dom Pedro Linhares, na Cidade do México. Este zoológico fantástico foi mapeado na forma de uma cartografia sobre os seres sobrenaturais que habitam uma imaginação mexicana.

Da mesma forma, comenta sobre as texturas dos sarapes tecidos pelas mãos de homens e mulheres em Teotitlan del Valle e os detalhes da técnica utilizada por três irmãs modeladoras do barro, ao reproduzirem escultoricamente as pinturas de Frida Kahlo. Ensaia uma biografia dos objetos artesanais, ao modo de Kopytoff, quando aborda as bonecas de trapo zapatistas, essas feitas por mulheres Chamula - mulheres indígenas, solidárias a causa do Exército Zapatista de Libertação Nacional; ou ainda, os milagres bordados de um grupo e mulheres urbanas de San Miguel.

Bartra articula suas interpretações com outras realizadas por pesquisadores (as) do Instituto de Investigações Estéticas da Universidade Autônoma do México, conferindo às suas uma proximidade com uma historiografia crítica da arte popular recente naquele país. Essa estratégia serve ao propósito desta autora de evidenciar que, de alguma forma, as investigações sobre a temática das culturas populares em espaços "subdesenvolvidos", são relevantes para entender os repertórios materiais e simbólicos que constituem a experiência moderna nesses centros urbanos.

É certo, que Bartra age com o desejo de dar visibilidade às gestualidades plásticas dessas mulheres, explicitando mais um espaço onde sua participação política, econômica, estética, histórica, pode constituír-se como uma forma de superação de um tipo de "dominação masculina" ou "patriarcado". Contudo, para isso, a autora estabelece uma fissura entre a ação política e estética, apresentadas como dimensões distintas, domínios que não sofrem influências mútuas, contaminações. Para sua construção teórica e empírica, Bartra obscurece as práticas coletivas que envolvem os homens e mulheres em espaços sociais populares, silencia as marcas dos diálogos entres esses sujeitos, que nas superfícies das obras, dão a dimensão daquelas formas de estar e viver o México contemporâneo, e nele se fazer mulher e homem, artistasartesãos. 
Em uma outra leitura possível da investigação, a autora define seu campo teórico como aquele da "História da Arte", interpretada, ou escrita, a partir das teorias feministas, constituíndo, assim, uma "História da Arte Feminista". $\mathrm{Na}$ forma de abordar este campo teórico, utilizando a lente de um tipo de teoria feminista pós-colonial, sua crítica recai, igualmente, sobre o feminismo.

Bartra considera que as teorias feministas originária dos países desenvolvidos (europeus e da América do Norte) desconsideram, na sua reflexão sobre o sujeito-histórico-mulher e sua produção material e simbólica, a arte popular. Para consolidar esta conclusão e crítica teórica (talvez epistemológica), a autora comenta que existe, no campo das reflexões feministas sobre a arte, uma "estratégia de esquecimento" dessa produção plástica - e portanto estética - que desloca a arte popular e as artistas populares para os "lugares" de sombra (subalterno), ou seja, para o anonimato.

Sua crítica a um tipo de teoria feminista apresenta-se como outra evidência da perspectiva equivocada da autora, na analise as assimetrias de gênero no campo das culturas populares. Ao ler de forma enviesada os diferentes locais que constituem este espaço social de produção de cultura material, Bartra restringe seu olhar a superfície das questões que envolvem as assimetrias de gênero nas culturas populares. Entre elas, a reorganização da família em função dos circuitos econômicos de troca; os deslocamentos das performances de masculinidade e feminilidade em espaços "tradicionais" e periféricos em função das mudanças e escolhas biográficas, entre outros fatores que influenciam positiva ou negativamente as gentes que constituem as culturas populares/subalternas.

A ausência de aprofundamento a respeito dos deslocamentos que acontecem no âmbito de instituições como a família, as práticas religiosas e políticas, inviabiliza ao (a) leitor (a) entender as estratégias que aquelas mulheres utilizam para dar conta dos processos de modernização das culturas populares em espaços urbanos recentes. Especialmente, aqueles atravessados por processos de globalização econômica e tensões interculturais, que influênciam os processos de atualização dos sistemas de objetos simbólicos/culturais em espaços urbanos e sociedades complexas como o México e a mexicana. Nesses espaços a diversidade de expressões populares materializa-se em sistemas de objetos diversificados, e em contínua atualização, como apresentado por Néstor García Canclini, Gobi Stromberg e Catherine Good Eshelman, entre outros.

O que fica ambíguo no texto de Bartra poderia ser resumido na seguinte questão: as atualizações que Bartra localiza no circuito de circulação simbólico no México tem a potência para caracterizar-se como estratégias políticas, estéticas e econômicas, utilizadas por essas mulheres-artesãs na sua liberação de um tipo de dominação masculina?

Ademais de questionar o que chamou de "Historia da Arte Feminista", em algumas passagens, sua crítica ao patriarcado e a um feminismo hegemônico toma a forma de panfleto ingênuo. Visto que, ela não oferece uma perespectiva teórica distinta àquela que avalia como equivocada ou limitada. Verdadeiramente, Bartra utiliza em sua investigação o mesmo instrumental 
teórico utilizado no que ela classifica por um feminismo hegemônico. Sob essa perspectiva, sua crítica às assimetrias de gênero "aparecem" no texto como incrustrações de reinvidicações por direitos e igualdade, que mais parece uma colagem, em que se pretende esconder as margens de cada elemento.

Outro motivo, apresentado pela autora para caracterizar sua crítica à um tipo de "História da Arte Feminista" é a inexistência de uma História da Arte Popular estruturada, com método, teoria e crítica, similar ao existente na disciplina já constituída no Ocidente. O que a autora quer dizer com isso, é que mesmo a historiografia da arte (pensada a partir de uma perspectiva hegemônica, ou seja, androcentrica) pouco se preocupou em problematizar a arte popular como sistema de objetos, ou obras de arte, com autores, que possuem trajetórias artísticas e influências estéticas, marcadas pelos processos históricos que influenciam suas produções e formas de circular e serem consumidas no mundo recente.

Como terceiro motivo para a inexistência de uma "Historia da Arte Popular" que evidencia a participação das mulheres, especialmente, aquelas indígenas e populares, Bartra cita a inexistência de manifestações das culturas populares nos países desenvolvidos, isso, comparado com aquelas dos países subdesenvolvidos. Esse fator, segundo a autora, demarca os interesses das investigadoras que definem os temas, as abordagens e a escritura de uma História da Arte Feminista.

De alguma forma, Bartra confere o desinteresse pela arte popular em centros urbanos "desenvolvidos", por parte das pesquisadoras feministas, em função de uma contingência desses espaços. Ou seja, por serem espaços socio-históricos urbanizados e modernizados, em que as práticas populares se manifestam com outras formas ou poéticas. Assim, Bartra radicaliza a diferença, e constrói sua crítica sobre o alicerce das assimetrias de poéticas de grupos populares tanto em países desenvolvidos, quanto naqueles sub-desenvolvidos, como a autora trata estes contextos.

Por fim, Bartra pretende expor que os sistemas de objetos populares são resultado do trabalho de pessoas concretas, que possuem desejos e limitações, origens específicas, características culturais e, principalmente gêneros definidos. E que o conceito de "arte popular" não passa da materialização de uma hierarquia forçada entre as manifestações da cultura material humana, que serve a um tipo de distinção de classes, já superada (a distinção entre o "popular" e o "culto"). Como resposta teórica a esta questão a autora apresenta uma conceituação de arte que parte da gestualidade, a saber: a "arte" seria entendida como uma criação ou conjunto de criações consideradas artísticas (sensíveis, talvez), com a autoria de homens e mulheres em espaços urbano.

Por meio dessas classificações, a autora pretende retomar o conceito de sincretismo. Por sincretismo, Bartra entende a combinação de coisas aparentemente distintas (distantes) e que não tem nenhuma relação entre si. Em seu esforço por reabilitar a noção de sincretismo, como uma categoria analítica para entender as culturas populares, a autora retira desse conceito sua vinculação com algum sistema filosófico ou religioso, cuja utilização representaria a combinação de doutrinas diferentes. Para Bartra a potência do 
conceito de sincretismo reside na possibilidade de conciliar coisas diferentes. Nesse movimento, a autora acredita que a combinação de elementos artísticos de diferentes esferas sociais (populares e eruditas, subalternas e hegemônicas), produz objetos interessantes do ponte de vista estético.

Com a reabilitação da noção de sincretismo, Bartra parece esquecer das discussões teóricas, ocorridas no decorrer das décadas de 1980 e 1990, sobre as categorias que pretendiam dar conta dos processos de modernização de grupos sociais, sociedades complexas pós-coloniais, ou mesmo, indivíduos em meio ao mundo recente (fosse ele moderno ou pós-moderno), a saber: hibridismo, refuncionalização, entre outras. Por mais que a autora pretenda higienizar a categoria de sincretismo, essa é marcada pelo estabelecimento de relações assimétricas de poder e participação, por parte de quem está envolvido na "combinação", sejam sujeitos em relações de trocas simbólicas, seja sociedades em processos de contato intercultural.

Assim, Bartra parece obscurecer os conflitos que marcam todos os processos de hibridismo. Expondo as formas resultantes de tais processos como um admirável mundo novo dos objetos sincréticos. O resultado disso é uma exaltação aos discursos da equivalência cultural e da aproximação de repertórios simbólicos em detrimento da explicitação do sistema dos objetos como mais uma arena de disputas políticas, entre outras, identitárias e de gênero. 